\title{
Recorregut de recerca geològica, geoambiental i mineralògica per la comarca del Baix Llobregat: des d'Esparreguera a Collbató i de nou cap a Esparreguera
}

Josep Maria Mata-Perelló

Joaquim Sanz Balagué

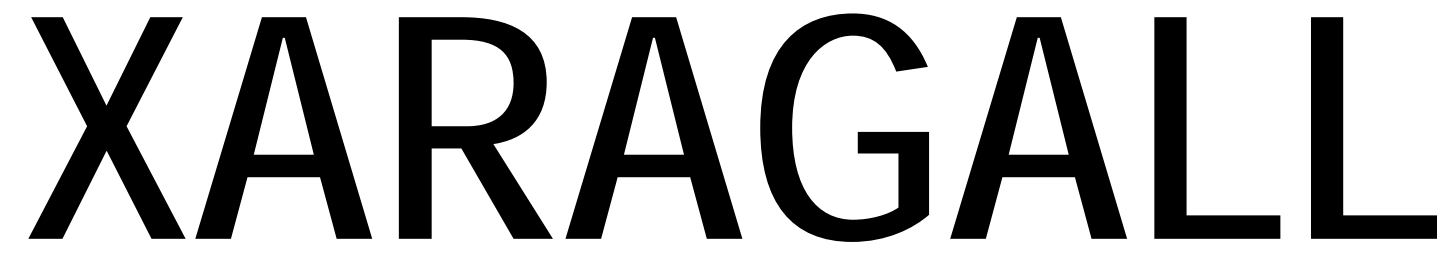

REVISTA DE CIÈNCIES DE LA CATALUNYA CENTRAL

n. 3

MARÇ 2014

Com citar l'article: Autor/s principal/s de la contribució. Títol de la contribució. Element d'enllaç (A:)* Títol de la revista [tipus de suport]: subtítol*. Edició o versió. Lloc de publicació: Editor, data de publicació, Localització de la contribució (vol, núm., pàg., ...). ISSN o altre identificador normalitzat. Notes* [Data de consulta] (obligatori per als documents en línia; opcional per als altres). Disponibilitat i accés (obligatori per als documents en línia; opcional per als altres). 


\title{
RECORREGUT DE RECERCA GEOLÒgICA, GEOAMBIENTAL I MINERALÒGICA PER LA COMARCA DEL BAIX LLOBREGAT: DES D'ESPARREGUERA A COLLBATÓ I DE NOU CAP A ESPARREGUERA
}

\author{
Josep Maria Mata-Perelló \\ Museu de geologia Valentí Masachs, Escola Politècnica Superior d'Enginyeria de Manresa \\ (EPSEM), Universitat Politècnica de Catalunya · BarcelonaTech (UPC), 08272 Manresa, Spain

\section{Joaquim Sanz Balagué} \\ Departament d'Enginyeria Minera i Recursos Naturals (EMRN), Escola Politècnica Superior \\ d'Enginyeria de Manresa (EPSEM), Universitat Politècnica de Catalunya · BarcelonaTech \\ (UPC), 08272 Manresa, Spain
}

Paraules clau: Sistema Mediterrani; Depressió geològica de l'Ebre; materials paleozoics i cenozoics; Miocè

\begin{abstract}
Resum
Itinerari realitzat el 13 d'abril del 2013. El recorregut del present itinerari discorrerà, en la seva totalitat per una sola unitat geològica: pel Sistema Mediterrani (i més concretament, ho farà per dues de les quatre sotsunitats que el constitueixen: per la Depressió Prelitoral Catalana (per on s'iniciarà i finalitzarà el recorregut, a la població d’Esparreguera) i per la Serralada Prelitoral Catalana (per on es desenvoluparà la major part del recorregut). Tot i així, molt breument es passarà també per la Depressió Geològica de l'Ebre, pels voltants de Collbató i molt puntualment.
\end{abstract}

Així, l'itinerari s'iniciarà a la localitat d'Esparreguera, d'on s'anirà cap als voltants de la població de Collbató, per a retornar finalment a Esparreguera. Així, I'haurem iniciat dintre de la Depressió Prelitoral Catalana, entrant després a la Serralada Prelitoral Catalana, per a finalitzar el trajecte de nou a la Depressió Prelitoral Catalana. I com hem dit abans, també haurem tocat molt tangencialment la Depressió Geològica de l'Ebre, prop de Collbató.

Per d'altra banda, el recorregut de l'itinerari, s'haurà desenvolupat totalment dintre de la comarca del Baix Llobregat. I més concretament, haurem circulat pels termes municipals de d’Esparreguera i de Collbató. 


\section{Objectius fonamentals}

Els objectius fonamentals que es pretenen aconseguir en el recorregut d'aquest itinerari, es poden concretar en els següents aspectes generals:

1. Observació del Sistema Mediterrani, així com de les diferents sotsunitats que la constitueixen i per les quals discorre el recorregut del present itinerari. Concretament de la Depressió Prelitoral Catalana i de la Serralada Prelitoral Catalana.

2. Observació de la Depressió Geològica de l'Ebre, que veurem molt marginalment, pels voltants de Collbató.

3. Observació i descripció dels materials paleozoics (quasi exclusivament de l'Ordovicià, així com de diversos afloraments granítics) i dels mesozoics (del Triàsic), amb un clar predomini dels primers. Aquests materials constitueixen el subsòl la Serralada Prelitoral Catalana, pels voltants de les poblacions per les quals discorrerà el recorregut de l'itinerari.

4. Observació i descripció dels materials terciaris neògens (i més concretament del Miocè), els quals formen part de la Depressió Prelitoral Catalana, i que nosaltres trobarem pels voltants d'Esparreguera. Molt sovint, aquets materials es troben recoberts per terrenys detrítics quaternaris.

5. Observació de les estructures locals d'aquests materials esmentats als paràgrafs anteriors, al llarg del recorregut de l'itinerari, així com de les relacions existents entre les sotsunitats que constitueixen el Sistema Mediterrani per aquests indrets (concretament per la Depressió Prelitoral Catalana i la Serralada Prelitoral Catalana).

6. Observació i descripció dels materials cenozoics que formen part de la Depressió Geològica de l'Ebre, que veurem pels voltants de Collbató.

7. Observació, si s'escau, de diverses explotacions mineres, antigues i actuals, situades al recorregut de l'itinerari.

8. Interpretació dels impactes mediambientals provocats per les explotacions mineres sobre el Medi Natural i sobre el Medi Ambient. I en tot cas de les restauracions dutes a terme per tal de corregir els impactes.

9. Observació de Patrimoni Geològic i del Patrimoni Miner, que anirem trobant al llarg d'aquest itinerari.

\section{Antecedents bibliogràfics}

Pel que fa al recorregut del present itinerari, existeixen alguns antecedents parcials, de tipus bibliogràfic referent a diferents parts del recorregut del mateix; es tracta de MATA-PERELLÓ (1986, 1995, 2001, 2006, 2007. 2012a, 2012b i 2013). Trets d'aquests antecedents, no en tenim coneixement de cap altres.

Tot i així, farem esment d'un important treball de SOLE SABARÍS (1964), on es descriu un recorregut molt proper al que ara presentem, dintre d'un conjunt de recorreguts pels voltants de Barcelona.

Pel que fa a la descripció de les mineralitzacions de les comarques per les quals discorre I'itinerari, cal parlar d'un altre treball nostre, de MATA-PERELLÓ (1991), relatiu al conjunt de 
les mineralitzacions catalanes en general, distribuïdes per comarques, i esmentant-se les corresponents al Baix Llobregat.

I, finalment, pel que fa a l'estructura geològica de la zona per la qual discorre l'itinerari, farem esment dels treballs de: GUIMERÀ et altri (1982) i de RIBA et altri (1976). Tanmateix, farem esment de les fulles de IGME (1976a i 1976b) relativa a la zona per on discorre el recorregut del present itinerari.

També cal parlar del treball de MATA - PERELLÓ i FONT SOLDEVILA (1995), relatiu a una proposta de geomuseu per aquesta zona.

Tots aquests treballs referenciats, i d'altres, figuren esmentats per ordre alfabètic a l'apartat dedicat a la BIBLIOGRAFIA.

\section{Recorregut de l'itinerari}

L'iniciï del recorregut de l'itinerari, s'iniciarà a la població d'Esparreguera (situada al Baix Llobregat, com l'anterior). Prop del poble es realitzaran dues aturades, les primeres d'aquest recorregut. Tot seguit, el recorregut continuarà a peu, per la Serra de Mas Mercadé - Serra de Rubió, fins arribar a les immediacions de Collbató. Posteriorment, des d'aquí, el recorregut retornarà cap a Esparreguera, per on finalitzarà.

\section{Advertiment previ sobre el recorregut}

Com en altres recorreguts de recerca geològica i mineralògica ..., aquest constarà de diverses parades. Però, sols si es disposa del temps suficient, podrà efectuar-se passant per totes les parades i filloles. En cas contrari, recomanem prescindir de les anomenades parades condicionals.

Pel que fa als camins per on transitarà el recorregut de l'itinerari, cal dir que en general es trobaran en bones condicions. Tot i així, sempre que sigui possible, recomanem demanar la màxima informació, en relació al estat real dels camins. També cal dir que la major part $d^{\prime}$ aquest recorregut el farem a peu.

En qualsevol cas, cal tenir sempre una cura molt especial de respecte a la natura, al llarg de tot el recorregut; de l'itinerari.

\section{Descripció de l'itinerari}

Com ja es habitual, s'estructurarà en una sèrie d'estacions (parades o aturades), en les qual es faran descripcions geològiques o mineralògiques, si s'escau. En cada cas s'indicarà el número del mapa topogràfic a escala 1:50.000 on es troba l'indret. En aquest cas, el recorregut de 
I'itinerari passarà exclusivament per un dels fulls del mapa anterior. Concretament ho farà pels fulls 391 (o d'Igualada) i 392 (o de Sabadell) de I'"Instituto Geográfico y Catastral", realitzat a l'escala de 1:50.000. Així doncs, la relació i descripció de les aturades que composen aquest itinerari, és la següent:

\subsection{Parada 1. Pla de Can Font, (terme municipal d'Esparreguera, comarca del Baix Llobregat, subcomarca del Baix Llobregat - Nord). (Full 392).}

El recorregut de l'itinerari caldrà iniciar-lo a Esparreguera, concretament al camí que es dirigeix cap a Collbató, per les proximitats del Pla de Can Font. Aquí mateix ens caldrà fer una nova aturada, aproximadament a uns $0^{\prime} 5 \mathrm{Km}$ de la sortida des d'Esparreguera.

En aquest breu recorregut, hem trobat afloraments dels materials quaternaris (o del terciari superior), fonamentalment de l'Holocè, els quals cobreixen als sediments miocènics de la Depressió Prelitoral Catalana. Des d'aquest indret, es pot veure una ampla panoràmica del Torrent de Roques Blaves, per sobre del qual estem situats. Així es veuen interessants exemples de xaragalls desenvolupats sobre aquests materials. Així cal dir que es tracta de llicorelles trinxades per la falla Nord del Vallès -Penedès, de color blavós. (fotografies 1 i 2)

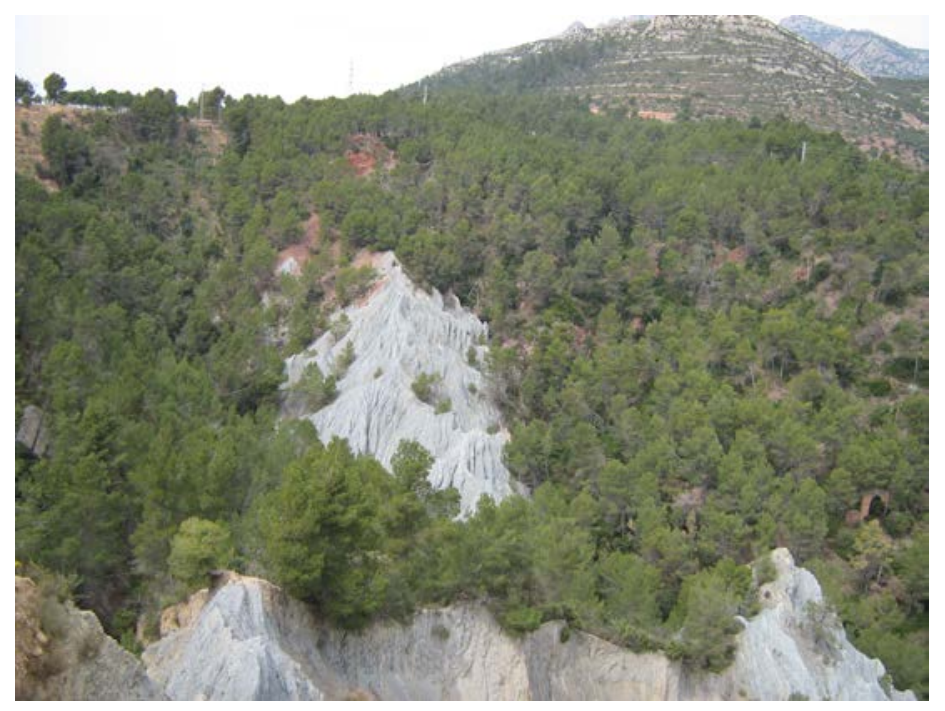

FOTOGRAFIA 1 . Xaragall de Roques Blaves, Esparreguera 


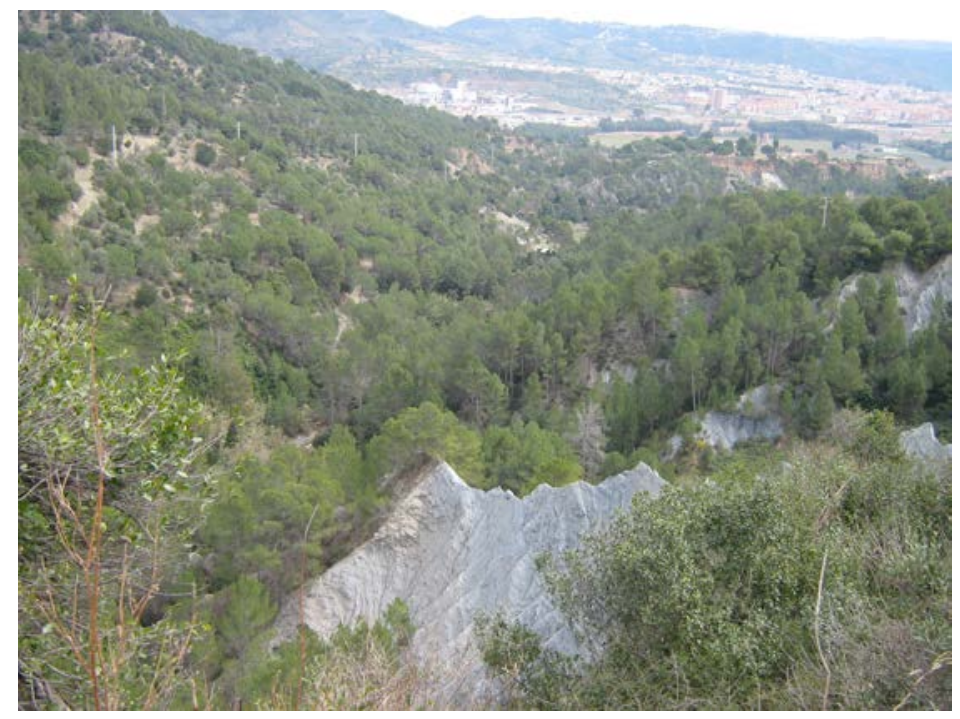

FOTOGRAFIA 2. Un altres aspecte del xaragall de Roques Blaves, Esparreguera

En relació a la falla, hem de dir que no la veiem, encara que estem situats davant de la seva bretxa de falla: les llicorelles trinxades que hem acabat d'esmentar. Aquesta falla posa en contacte les llicorelles paleozoiques situades al Nord d'on ara som, i els materials detrítics del Miocè, situats al Sud. Les primeres es troben a la Serralada Prelitoral Catalana; mentre que les segones es troben a la Depressió Prelitoral Catalana.

Tanmateix, mirant a l'altra banda del torrent, es pot veure una falla que posa en contacte els materials rogencs del Buntsandsteim amb les llicorelles de I'Ordovicià. La falla es vertical i es fa palesa a diferents zones, enfront nostre.

Des d'aquest lloc es pot gaudir de l'observació (a l'altra banda del torrent) dels diferents materials triàsics, donant lloc a un interessant tall. Així, sobre els gresos i calcolutites rogenques del Triàsic Inferior (del Buntsandsteim), es poden veure els diferents trams del Triàsic Mitjà: les calcàries i dolomies del Muschelkalk Inferior, els gresos i calcolutites roges del Muschelkalk Mig i les calcàries i dolomies del Muschelkalk Superior, al Coll de Can Colomer. (fotografia 3).

Tanmateix, per darrera de tots els materials anteriors, es poden veure els nivells de conglomerats i bretxes calcaries de l'Eocè, tot formant part de Montserrat. Precisament, aquesta muntanya es fa ja clarament palesa per darrera dels materials mesozoics, tot i que entre uns i altres hi ha la Riera de la Salut, que baixa al Llobregat pels voltants de Ca n'Estruc. 


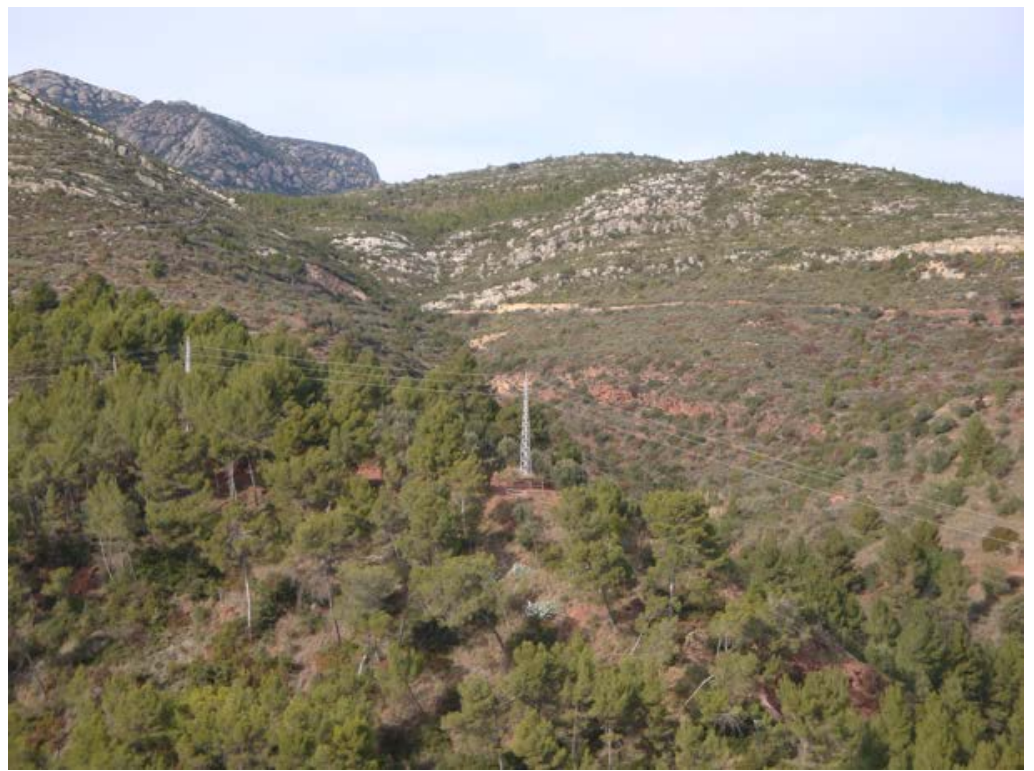

FOTOGRAFIA 3. Sèrie triàsica al torrent de Mas Mercader. A la part baixa hi ha els materials del Buntsadsteim (amb gresos i calcolutites). Per sobre les calcaries i dolomies del Muschelkalk Inferior, més amunt el terrenys rogencs del Muschelkalk Mig (amb gresos i calcolutites). I més amunt a l'esquerra, els terrenys carbonatats del Muschelkalk Superior. Per sobre de tots, al darrere, els conglomerats de l'Eocè, de Montserrat.

Finalment, cal dir que aquest paratge on ara som, és un indret molt interessant del nostre patrimoni geològic, que cal conservar adequadament.

\subsection{Parada 2 - condicional. Polígon industrial d’Esparreguera. Fàbrica Fitxet, (terme municipal d'Esparreguera, comarca del Baix Llobregat, subcomarca del Baix Llobregat - Nord). (Full 392).}

Després de realitzar la parada anterior, cal continuar pel camí que es dirigeix cap a Can Rubió (i cap a la Font de la Mola). En arribar al polígon industrial, podem fer una nova aturada, si s'escau, a uns $0^{\prime} 2 \mathrm{Km}$ de l'anterior.

En aquest recorregut, hem trobat fonamentalment afloraments dels materials recents de I'Holocè, fonamentalment. Aquests terrenys son depòsits de peudemont amb graves i arenes que cobreixen als materials paleozoics. En alguns indrets del polígon, arriben a veure's aquests materials de I'ordovicià, constituïts per pissarres, fonamentalment.

\subsection{Parada 3. Can Rubió, (terme municipal d’Esparreguera, comarca del Baix Llobregat, subcomarca del Baix Llobregat - Nord). (Full 392).}

Després de realitzar la parada anterior, cal continuar pel camí que es dirigeix cap el WNO, anant cap a la casa de Can Rubió. Aquesta es troba situada al peu de la serra del mateix nom. En arribar-hi, després de recórrer uns 0’2 Km més, podem fer una nova aturada. 
En bona part d'aquest recorregut, hem anat trobant afloraments dels materials detrítics de I'Holocè, els quals van cobrint als terrenys paleozoics de l'Ordovicià (que apareixen constituïts per llicorelles). Més amunt, haurem trobat afloraments dels materials rogencs del Buntsandsteim, del Triàsic Inferior, constituïts per trams de gresos i de calcolutites. I més amunt, per sobre de la casa, apareixen els nivells carbonatats del Muschelkalk Inferior (del Triàsic Mig). El que no hem trobat és el contacte entre els materials de l'Ordovicià i els del Triàsic, ja que possiblement es troba fossilitzat pels terrenys detrítics de l'Holocè. Tot això, el podem veure molt esquematitzat a l'esquema 1.

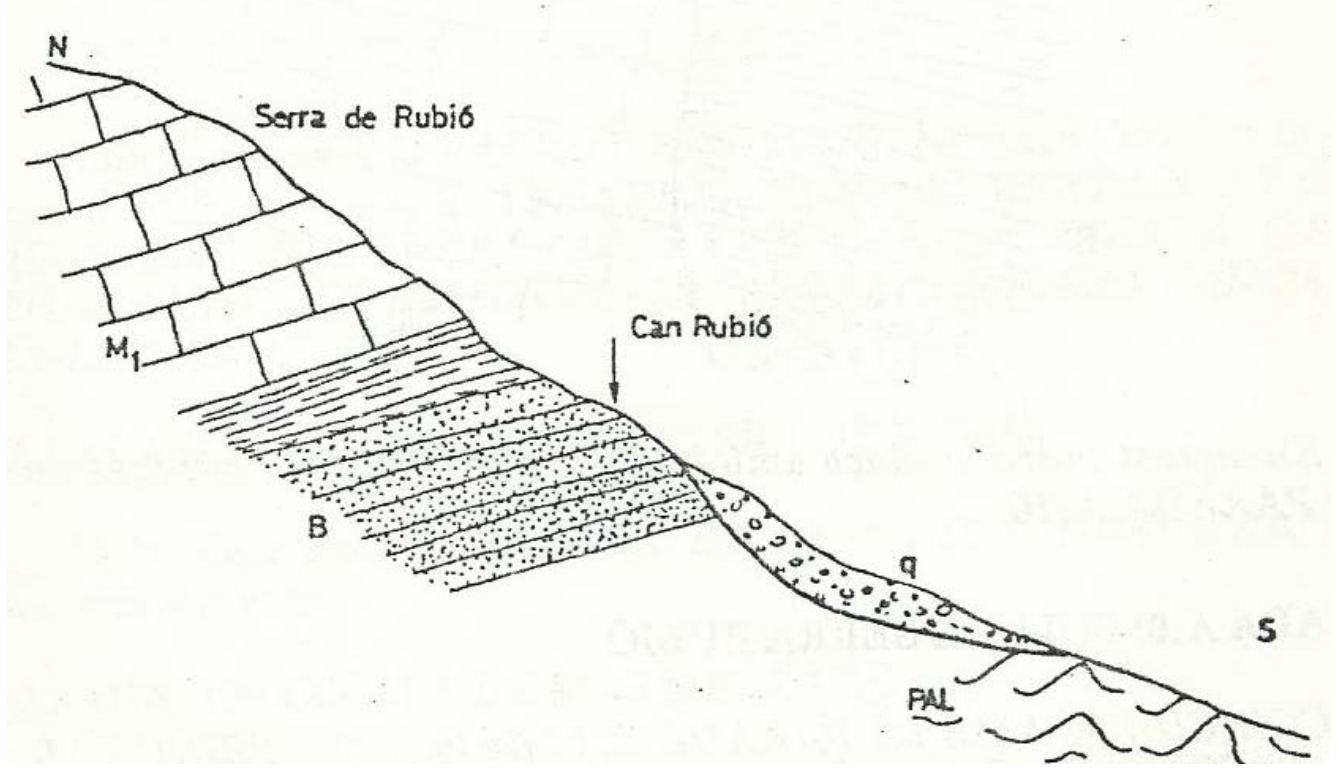

ESQUEMA 1. Materials de I'Ordovicià i del Triàsic, prop de Can Rubió. Els terrenys de I'Holocè (q) fossilitzen el contacte entre els terrenys paleozoics i els mesozoics

\subsection{Parada 4. Collet Gatells, (terme d’Esparreguera, comarca del Baix Llobregat, subcomarca del Baix Llobregat - Nord). (Full 392).}

Des de la parada anterior, cal agafar el camí que es dirigeix cap el Coll de Serra Rubió i cap a Collbató, passant pel barranc de Gatells i també pel collet del mateix nom. En arribar a aquest indret farem una nova aturada, a menys de 0’2 $\mathrm{Km}$ de la parada anterior.

En aquest recorregut, en sortir de Can Rubió, hem anat tallant afloraments dels materials triàsics del Buntsandsteim, formats per gresos i calcolutites rogenques. Més amunt, però aviat, començarem a trobar nivells de carbonatats (calcàries i dolomies) del Muschelkalk Inferior.

En arribar al collet veurem una falla, que posa en contacte els materials detrítics rogencs del Buntsandsteim amb els nivells carbonatats del Muschelkalk Inferior. Així, en alguns indrets del torrent de Gatells, es veuen a la riba esquerra els materials rogencs del Buntsandsteim, mentre que a la riba dreta es troben els del Muschelkalk Inferior. Aquest contacte es pot entreveure a l'esquema 2. 


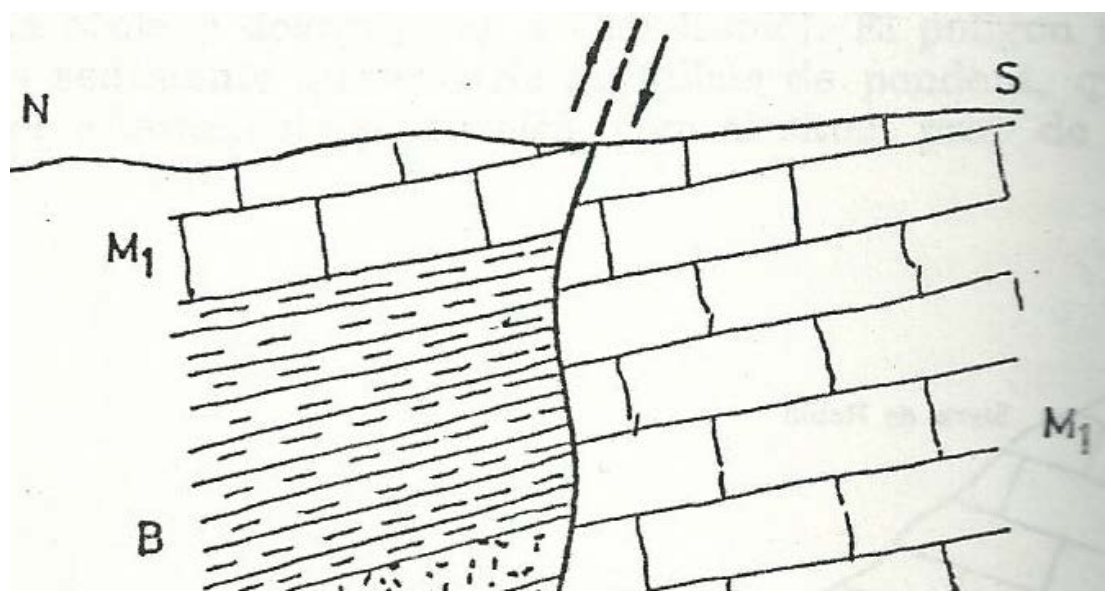

Esquema 2. Falla del Coll de Gatells

\subsection{Parada 5. Coll de la Serra Rubió, (terme d’Esparreguera, comarca del Baix Llobregat, subcomarca del Baix Llobregat - Nord). (Full 392).}

Des de l'aturada anterior, cal continuar per camí que es dirigeix cap al collet de la Serra Rubió i que procedeix de Can Rubió. En arribar al Collet, podem fer una nova aturada, aproximadament a uns $0^{\prime} 25 \mathrm{Km}$ de la parada anterior. Cal dir que per aquest indret hi ha una casa nova, quasi construïda al bell mig del camí, que obliga a fer un petit revolt.

En aquest recorregut, es van tallant els nivells rogencs del Buntsandsteim formats pels nivells de gresos i de calcolutites rogenques. En arribar al coll, es troben els nivells de conglomerats basals d'aquest tram del Triàsic, constituïts per nivells de conglomerats i fins i tot de bretxes. Aquests materials es troben en posició vertical, amb les pissarres del Paleozoic (concretament de I'Ordovicià). Una interpretació aproximada es pot veure a l'ESQUEMA 3.

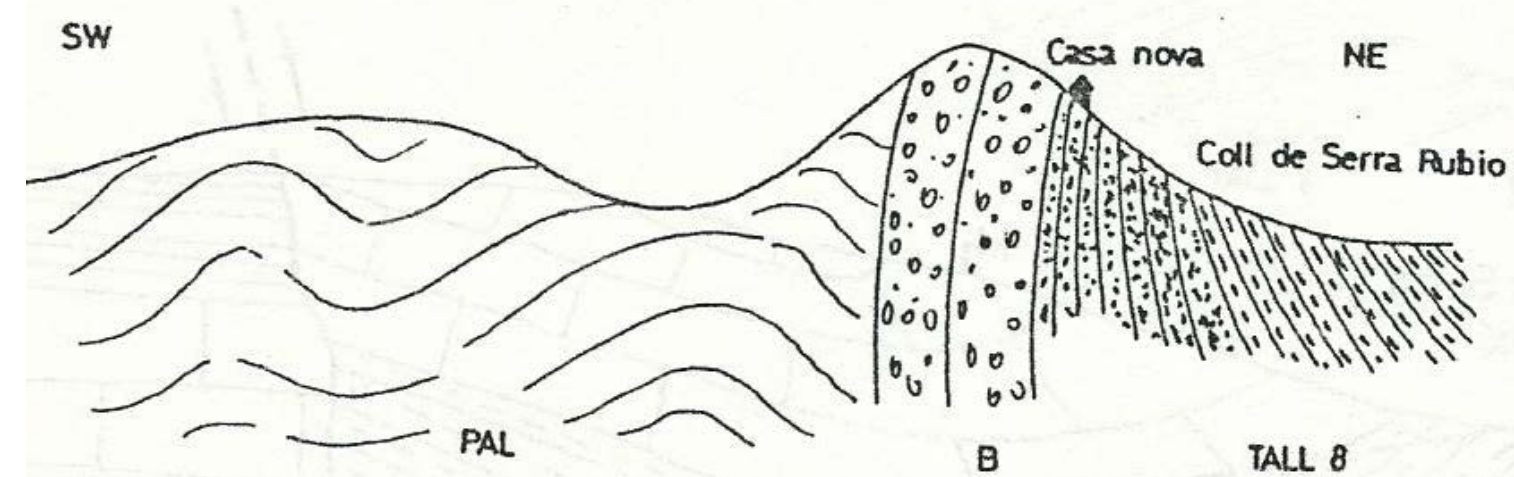

ESQUEMA 3. Falla del Coll de Gatells

Per d'altra banda, ben a prop del coll, a uns 50 metres (aproximadament), després de l'inici del camí que es dirigeix cap a Collbató, hi ha un indici de mineralització cuprífera associada a "redbed". En efecte, es troben indicis d'ATZURITA i de MALAQUITA, molt prop del camí que anem seguint. 


\subsection{PARADA 6. Pedreres de Collbató, (terme municipal de Collbató, comarca del Baix Llobregat, subcomarca del Baix Llobregat - Nord). (Full 392)}

Després de realitzar la parada anterior, cal continuar pel camí que es dirigeix cap al proper poble de Collbató. Poc abans d'arribar-hi, trobarem una antiga pedrera situada al costat del camí que anem seguint. En aquest indret, situat a uns 0 '5 Km de la parada anterior, en podem fer una altra.

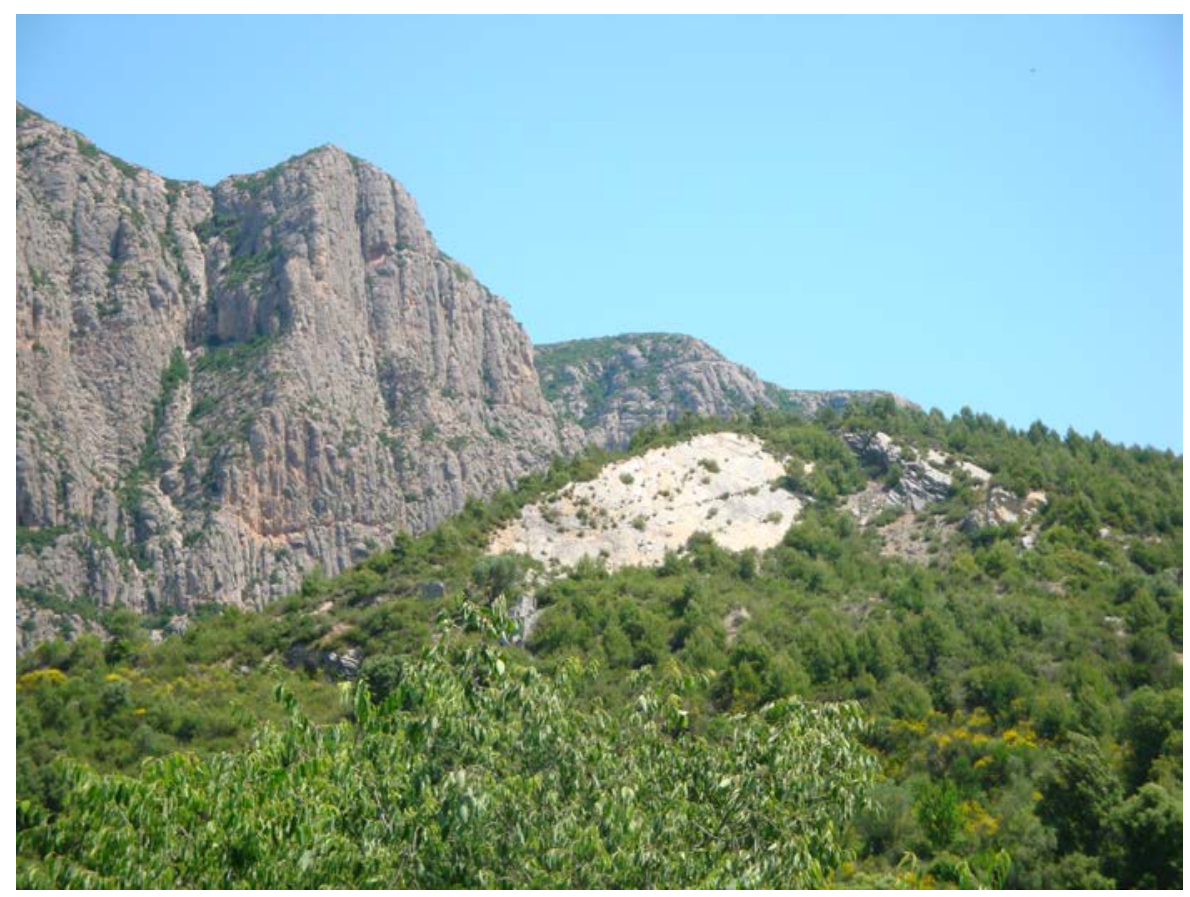

FOTOGRAFIA 4. Un aspecte llunyà de I'explotació (des del poble), amb Montserrat al fons

En aquest recorregut, es tornen a tallar els diferents materials del Muschelkalk; primer els del tram inferior, que hem vist molt prop de la parada anterior. Tot seguit, haurem trobat els trams rogencs del Muskelkalk Mig, amb nivells de gresos i de calcolutites rogenques. I, finalment, haurem trobat els nivells carbonatats (calcaries, fonamentalment) del Muschelkalk Superior.

Poc abans d'arribar a Collbató, es passa per una antiga pedrera, localitzada entre els nivells de calcàries $\mathrm{i}$ de dolomies del Muschelkalk Superior, les quals eren explotades. Dintre de la pedrera, les calcàries presenten un clar cabussament cap al Nord. A I'actualitat es troba aturada l'explotació. FOTOGRAFIA 4.

\subsection{PARADA 7. Pedrera i forns de calç de Collbató, (terme municipal de Collbató, comarca del Baix Llobregat, subcomarca del Baix Llobregat - Nord). (Full 392)}


Després de realitzar l'aturada anterior, cal continuar pel camí, anant sempre a peu. Aquest camí s'apropa cada vegada més a Collbató i a la carretera local de Collbató a Monistrol, la B 231. Poc abans d'arribar-hi, es troben uns antics forn de calç. I poc després, en arribar a la carretera hi ha una antiga explotació (a uns 75 metres dels forns). En aquest sector, farem una nova aturada, entre uns 200 i uns 300 metres des de la parada anterior.

En aquest recorregut, hem anat trobant afloraments dels materials carbonatats, ja esmentats a les aturades anteriors. Aquest són els que apareixen en aquest indret i també els que es van explotar a la bora de la carretera. FOTOGRAFIA 5.

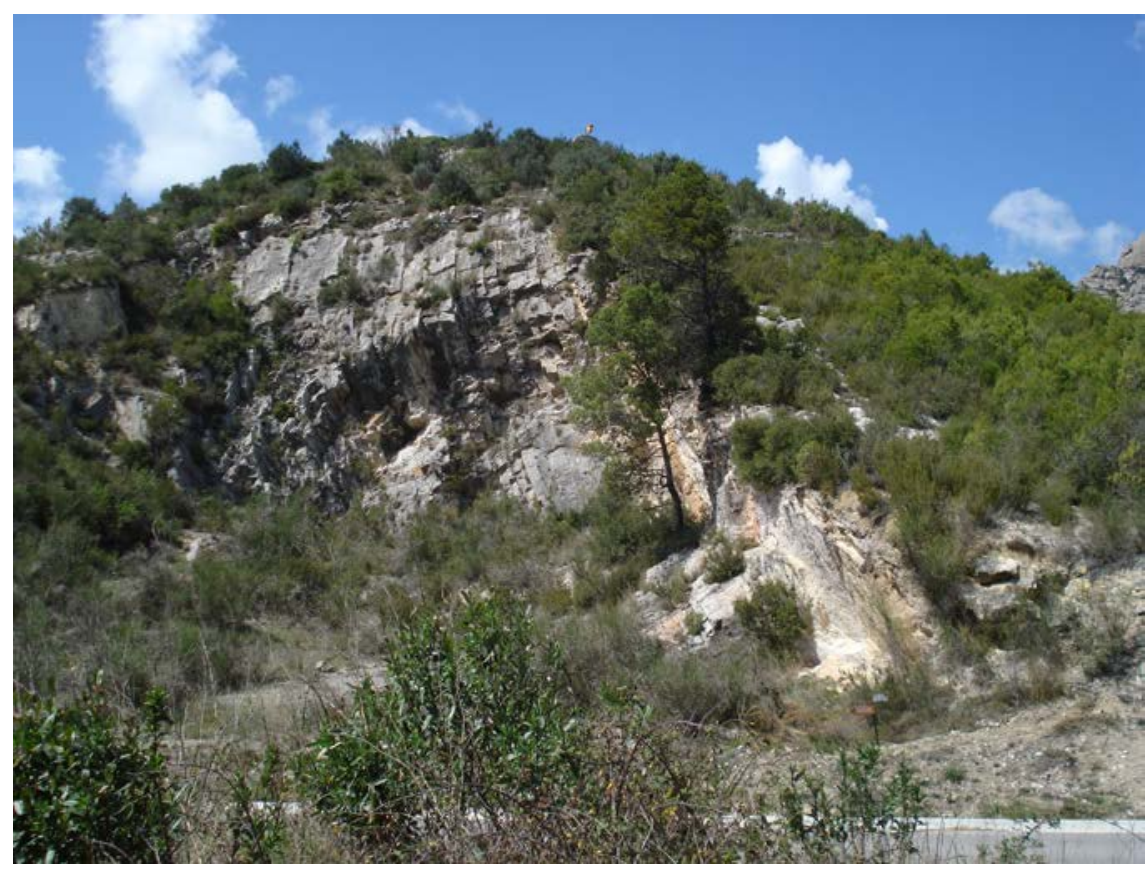

FOTOGRAFIA 5. Antiga pedrera de calcàries situada a la bora de la carretera de Collbató a Monistrol

Per d'altra banda, abans d'arribar a la carretera, haurem trobat un interessant conjunt de forns de calç. En ells s'utilitzaven els materials estrets a la pedrera que acabem d'esmentar. Es tracta d'un important conjunt patrimonial (fotografia 6), que forma part del Geoparc de la Catalunya Central. Alhora també és un important indret patrimonial de la comarca del Baix Llobregat. 


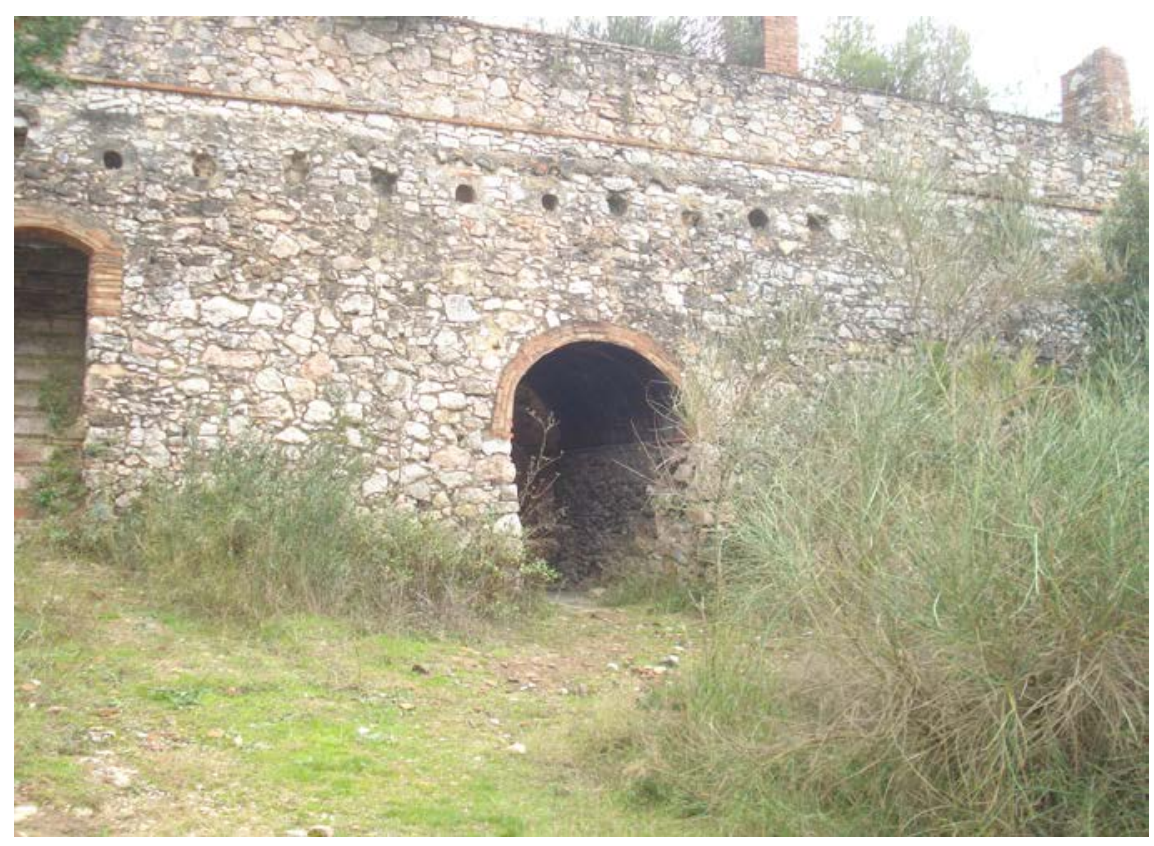

Fotografia 6 Un aspecte de la part frontal dels Forns de Calç de Collbató.

\subsection{Parada 8. Trencall de la Cova del Salnitre, Carretera de Collbató a Monistrol, (terme municipal de Collbató, comarca del Baix Llobregat). (Full 392)}

Després de fer l'aturada anterior, cal continuar ara per la carretera B-231 (tot fent una fillola), anant cap cap al NE, cap al poble de Monistrol de Montserrat i cap a I'Aeri de Montserrat. Ben aviat arribarem al Collet de Collbató. I més endavant, a uns 300 metres d'ell, es trobarà el trencall (per l'esquerra de la carretera) que es dirigeix cap a la Cova del Salnitre. En aquest trencall realitzarem una nova aturada. Així, haurem recorregut aquests 0 '3 $\mathrm{Km}$ des de la parada anterior.

En aquest recorregut haurem anat trobant inicialment els materials carbonats esmentats a l'aturada anterior. Però ben aviat, al mateix coll, trobarem uns afloraments de materials rogencs eminentment detrítics. Aquests materials pertanyen segons els llocs a la Formació Carme (del Grup Pontils) o a la Formació Montserrat, predominant cada cop més aquests darrers. En el primer cas es tracta de nivells de gresos i el segon de conglomerats. Aquests materials ja pertanyen a la Depressió Geològica de l'Ebre. Es a dir, en aquest trajecte hem passat de la Serralada Prelitoral del Sistema Mediterrani a la Depressió Geològica de l'Ebre.

Tot i així, a l'indret d'on eix el trencall cap a la cova, es poden veure uns afloraments d'uns materials que pertanyen probablement al Keuper (amb carnioles, lutites i calcàries, que desserveixen un petit anticlinal). Per sobre d'aquests es troben els nivells rogencs abans esmentats. (fotografia 7). Per d'altra banda, sobretots aquests materials s'observen abundants derrubis de pendent, quaternaris. 


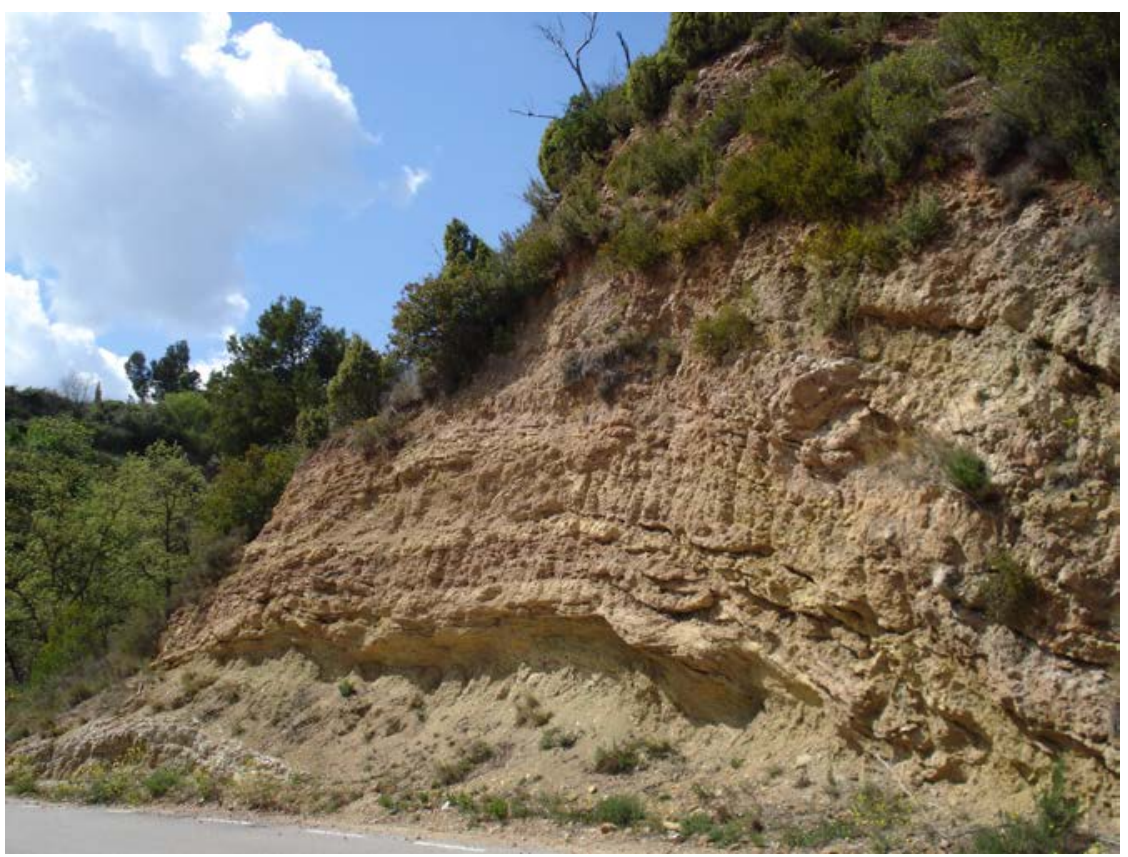

Fotografía 7. Materials del Triàsic (calcaries del Muschelkalk i carnioles del Keuper), descrivint un petit anticlinal

Per d'altra banda, a l'indret de la parada apareixen les calcàries del Muschelkalk, (com ja hem dit anteriorment) i també els nivells de carnioles del Keuper; però prop d'aquest lloc es veu el contacte entre aquests materials de la Serralada Prelitoral Catalana, amb els nivells de lutites i gresos rogencs de la Depressió Geològica de l'Ebre, situats per sota dels conglomerats de Montserrat, que des d'aquí es fan molt palesos. Aquests materials rogencs pertanyen al Cenozoic, i probablement són del Paleocè.

Per d'altra banda, caldria dir que més amunt, des d'aquí es fan palesos els trams de conglomerats, els materials que configuren la muntanya de Montserrat.

\subsection{Parada 9. carretera $b-431$, al seu pas pel poble de Collbató, (terme municipal de Collbató, comarca del Baix Llobregat, subcomarca del Baix Llobregat - Nord). (Full 392)}

Després de realitzar l'aturada anterior, cal retornar cap l'indret on hem fet la PARADA 7, per tal de continuar per la carretera local B - 431, anant ara cap al poble de Collbató, que ja és a tocar d'on ara som. En arribar al poble, farem una nova aturada, al costat de la mateixa carretera. Així, haurem recorregut uns 0’5 Km, aproximadament.

En aquest recorregut, hem trobat inicialment els materials que ja hem vist a l'aturada 7, és a dir: les calcàries (i dolomies) del Muschelkalk. Tanmateix, anant cap a Collbató, trobarem uns afloraments de gresos i calcolutites, que també pertanyem al Muschelkalk, concretament al Mig. Més endavant, anant cap el poble, però molt prop d'ell, tornarem a trobar nivells de carbonats, del Muschelkalk Inferior, prop del contacte amb els gresos i calcolutites rogenques del Buntsandsteim. Molt sovint, aquests contactes són estructurals, ja que en aquest tram s'observen diferents fractures al llarg de tot aquest recorregut. 
Finalment, prop del poble, trobarem uns afloraments de llicorelles paleozoiques que pertanyen a l'Ordovicià. Aquests darrers són els terrenys que apareixen a la carretera, al poble. (fotografia 8).

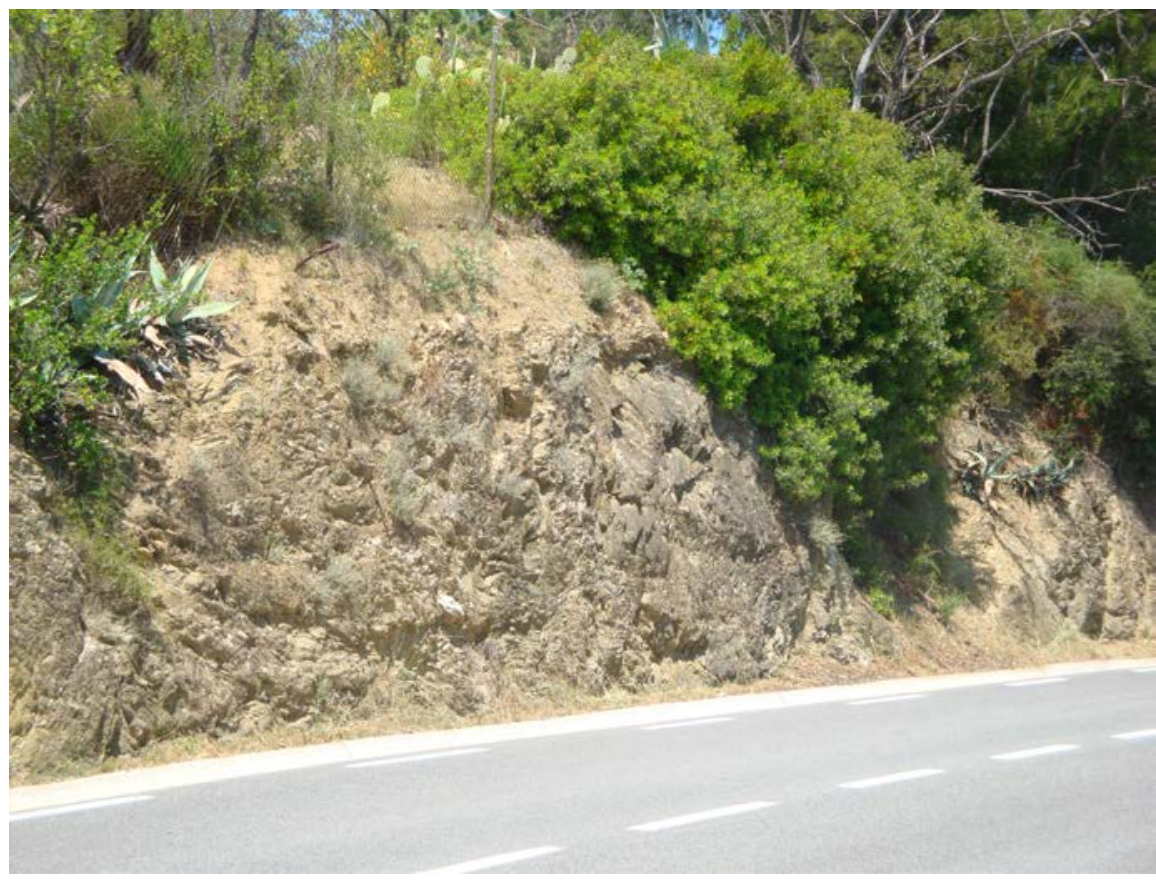

FOTOGRAFÍA 8. Les llicorelles de l'Ordovicià a Collbató. Carretera a Monistrol de Montserrat

\subsection{Parada $\mathbf{1 0}$ - condicional. antiga carretera $\mathbf{n}$ - ii, immediacions del polígon industrial d'Esparreguera,(terme municipal d'Esparreguera, comarca del Baix Llobregat, subcomarca del Baix Llobregat - Nord). (Full 392).}

Després de realitzar la parada anterior, cal retornar cap a Esparreguera. Per fer-ho, podem utilitzar algun camí paral-lel a l'autovia, fins a trobar l'antiga carretera $\mathrm{N}-\mathrm{II}$, al seu pas pel Polígon Industrial. Aquí, farem la darrera aturada, a uns $4 \mathrm{Km}$ de I'anterior.

En aquest recorregut, hem anat trobant força afloraments de materials detrítics de l'Holocè. Aquests materials cobreixen als terrenys paleozoics que hem vist a l'aturada anterior. Molt ocasionalment, per sota d'aquests materials recents, apareixen les llicorelles paleozoiques de I'Ordovicià.

Aquí finalitza el recorregut de l' itinerari, a un indret molt proper on haurem fet l'aturada 2 


\section{Referències bibliogràfiques}

GUIMERÀ, J. et altri (1992).- Geologia (II), Història Natural dels Països Catalans, Vol.2, 547 pag. Enciclopèdia Catalana, S.A. Barcelona

IGME (1975).- Explicación del Mapa Geològico de España, a escala 1:50.000. Segunda serie. Hojas número: 391 (Igualada), IGME. Madrid

MATA - PERELLÓ, J.M. (1986).- Itineraris geològics per Esparreguera i Collbató. Xaragall, ${ }^{\circ}$ 11. 37 pag. Manresa

MATA - PERELLÓ, J.M. (1991).- Els Minerals de Catalunya. Arxius de la Secció de Ciències, t. XCIII, 442 pag. Institut d’Estudis Catalans. Barcelona

MATA-PERELLÓ, J.M. (1997).- Recerca Geològica i Mineralògica per les comarques del Baix Llobregat i del Vallès Occidental: des de Castellbisbal a Martorell i a Esparreguera. Inèdit, 12 pàgines. Manresa

MATA-PERELLÓ, J.M. (2001).- Recorregut de recerca geològica i mineralògica per les comarques del Baix Llobregat i del Vallès Occidental: des de Terrassa i Castellbisbal a Sant Cugat del Vallès i al Papiol, i des de Martorell a Olesa de Montserrat i a Esparreguera. Algeps, sèrie $B, n^{0} 159,14$ pag. Manresa

MATA-PERELLÓ, J.M. (2006).- ).- Recorregut de recerca geològica, geoambiental i mineralògica per les comarques del Baix Llobregat i d'Anoia: des d'Esparreguera a Piera i a la Pobla de Claramunt. Inèdit. 14 pàgines. Manresa

MATA-PERELLÓ, J.M. (2007).- Recorregut de recerca geològica, geoambiental i mineralògica per les comarques del Baix Llobregat i d'Anoia: des d'Esparreguera a Piera i a la Pobla de Claramunt. Inèdit. 14 pàgines. Manresa

MATA-PERELLÓ, J.M. (2012a).- Recorregut de recerca geològica, geoambiental i mineralògica per les comarques del Baix Llobregat i d'Anoia: des d'Olesa de Montserrat i Esparreguera a Pierola, Piera, Vallbona i a Capellades. Inèdit. 14 pàgines. Manresa

MATA-PERELLÓ, J.M. (2012b).- Modificacions al recorregut de recerca geològica, geoambiental i mineralògica per les comarques del Baix Llobregat i d'Anoia: des d'Olesa de Montserrat i Esparreguera a Pierola, Piera i a Vallbona d’Anoia. Inèdit. 12 pàgines. Manresa

MATA-PERELLÓ, J.M. (2013).- Sortida de recorregut geològic pel Geoparc de la Catalunya Central i terres els voltants (comarques d'Anoia, Baix Llobregat i Bages: des del Bruc a Collbató, a l'Aeri de Montserrat, Monistrol de Montserrat, Castellbell, Marganell i a Can Maçana. Inèdit. 18 pàgines. Manresa

MATA-PERELLÓ, J.M. i FONT SOLDEVILA,J. (1995).- El "Ecomuseu del riu Anoia", un instrumento didáctico para la enseñanza de la geologia. $1^{a}$ Reunión de la Comisión de Património Geológico de la Soc. Geol. España. Geogaceta, n² 20, 10 pag. Madrid

RIBA,O. (1967).- Resultados de un estudio sobre el terciário continental de la parte Este de la Depresión Central Catalana. Acta Geológica Hispánica, t.. 2, Vol.1, pp. 3-8. Barcelona

RIBA, O. et altri (1976).- Geografia Física dels Països Catalans, Edit. Ketres, 254 pàgines. Barcelona

SOLÉ SABARÍS, L. (1964).- Geologia de los alrededores de Barcelona. Colección la "Nueva Geografia", Minist. de Educ. Nacional. 135 pag. Barcelona 